\title{
The Effects of Tax Reduction and Fee Reduction Policies on the Digital Economy
}

\author{
Tuochen Li and Liang Yang *(1) \\ School of Economics and Management, Harbin Engineering University, Harbin 150001, China; \\ lituochen0409@163.com \\ * Correspondence: yangliang2018@hrbeu.edu.cn
}

Citation: Li, T.; Yang, L. The Effects of Tax Reduction and Fee Reduction Policies on the Digital Economy. Sustainability 2021, 13, 7611. https:// doi.org/10.3390/su13147611

Academic Editor: Ştefan Cristian Gherghina

Received: 5 May 2021

Accepted: 17 June 2021

Published: 7 July 2021

Publisher's Note: MDPI stays neutral with regard to jurisdictional claims in published maps and institutional affiliations.

Copyright: (c) 2021 by the authors. Licensee MDPI, Basel, Switzerland. This article is an open access article distributed under the terms and conditions of the Creative Commons Attribution (CC BY) license (https:// creativecommons.org/licenses/by/ $4.0 /)$.

\begin{abstract}
The digital economy is the future of the world in terms of both contemporary trends and opportunities. Developing the digital economy is a practical way of strategically re-thinking network power and digital China and is the only way to achieve successful growth in countries' development economies and seize a commanding position for future development. Tax reductions, which promote high-quality economic development and preserve the overall situation of national governance, are an important measure for all countries to cope with economic pressure. In recent years, China has successively introduced and continuously expanded a series of tax and fee reduction policies that have played an important role in stabilizing its economy and vigorously developing its digital economy. This study consists of six sections. The first section provides an overview of the digital economy, introducing its definitions and connotations as well as the significance of developments of the digital economy. The second section is a literature review of tax and fee reductions; the research results in this field for countries around the world are summarized based on the three perspectives of research objects, tax-reduction-policy effects and research methods and data. The third section describes the impact of tax reductions and fee reductions on China's digital economy from an international perspective. Through the 2019 Forbes Global Top 100 Digital Economy List, this article analyzes the global digital economy corporate structure, observes the positive effects of tax and fee reductions on Chinese digital economy companies and compares the impact of tax cuts and fee reductions on digital economy companies in China, the United States and other countries. Stata software was used to conduct an empirical analysis on the panel data of digital economy companies from both macro and micro perspectives and Analysis of the Effects of Tax and Fee Reduction Policies in the Digital Economy presents an evaluation of the policy effects of tax cuts and fee reductions on digital economy companies from multiple aspects. China does not have a systematic tax and fee reduction policy that is compatible with digital economy development and its investments in large digital economy companies can be increased, as discussed in Problems of Tax and Fee Reduction and Policies in China's Digital Economy. In Policy Recommendations for Tax and Fee Reductions in the Digital Economy, we recommend that China improves and optimizes its tax and fee policies to increase tax incentives for independent innovation and high-level talent.
\end{abstract}

Keywords: digital economy; tax reduction and fee reduction policies; policy effects

\section{Overview of the Digital Economy}

The digital economy is a contemporary global trend around the world and a modern economic revolution. Accelerating the expansion of the digital economy is the only way to achieve high-quality development in the future. The digital economy has become the new engine of the global economy. Enhancing the digital economy has gained momentum in China, where tax cuts and fee reductions are important measures that have been taken to deal with downward pressures of the economy, promote high-quality economic development and serve national governance. In recent years, China has successively introduced and continuously expanded a series of tax- and fee-reduction policies that have 
played an important role in maintaining the overall stability of the economy and vigorously developing the digital economy.

Based on big tax data and data from listed companies in the global digital economy, this paper analyzes and evaluates the policy effects of tax and fee reductions in the digital economy, explores existing problems and shortcomings and provides suggestions of how to facilitate the high-quality development of the digital economy and optimize tax policies.

\subsection{The Definition of Digital Economy}

An authoritative definition of the digital economy was given by the G20 Digital Economy Development and Cooperation Initiative, issued at the 2016 Hangzhou Summit. According to them, "digital economy" refers to a series of economic activities that use digital knowledge and information as key factors of production, modern information networks as important carriers and information and communication technologies as an important driving force for enhancing efficiency and optimizing economic structures. This definition of the digital economy from the G20 Hangzhou summit is widely recognized [1].

The digital economy includes two aspects: digital industrialization and industrial digitization. Digital industrialization promotes the formation and development of the digital industry through the market-oriented application of modern information technology, including emerging industries such as cloud computing, big data, the internet and artificial intelligence, as well as basic industries such as integrated circuits, high-end software, communication networks, new displays, new components and materials and cutting-edge technologies such as blockchain, virtual reality, quantum information and flexible electronics. Industrial digitization uses modern information technology to drastically transform traditional industries and improve total-factor productivity by promoting the integration of the internet, big data, artificial intelligence and the real economy, including intelligent transformation, network collaborative manufacturing, personalized customization, serviceoriented manufacturing, the "enterprise cloud," the industrial internet and the digital development of the life-service and productive-service industries [2].

To accelerate the decision-making arrangements for the construction of the National Digital Economy Demonstration Province, which comprehensively and scientifically reflects the development of the digital economy, the Ministry of Industry and Information Technology and the National Bureau of Statistics (Beijing, China), in accordance with the new industry classification catalog of the National Economic Industry Classification, defined the statistical scope of 128 small industries in the following seven broad categories as the core industries of the digital economy: computer communications and other electronic equipment manufacturing; electronic information electromechanical manufacturing; special electronic equipment manufacturing; telecommunications, radio and television and satellite transmission service; the internet and its related services; software and information technology services; and cultural digital content and its services.

\subsection{The Significance of Developing the Digital Economy}

1.2.1. Acceleration of the Development of the Digital Economy Due to International Competition

"International competition" refers to competition among countries for space and resources. With the arrival of the digital age, the newly created virtual space has opened up a new level of international competition. This has brought opportunities and challenges that seek to change the forces of all parties and reshape the world's political and economic patterns, attracting the attention of many countries. China has developed several leading enterprises in the digital economy such as Huawei (Shenzhen, China), Tencent (Shenzhen, China), Alibaba (Hangzhou, China) and Hikvision (Hangzhou, China). However, China's digital economy still faces problems such as weak core technological innovation capabilities, insufficient integration and application depth in manufacturing, imbalanced regional development and insufficient support for digital infrastructure; it still faces a big gap with developed countries. 
1.2.2. Acceleration of the Development of the Digital Economy to Restart Economic Momentum after COVID-19

During the COVID-19 pandemic, the digital economy's lack of time and space restrictions has been highlighted. New forms of e-commerce such as online shopping, remote working and online services have played an important role in the fight against the pandemic. The potential of new technologies such as big data, artificial intelligence and cloud computing to transform and upgrade traditional industries has emerged. In the short term, the digital economy has helped the offline economy through the pandemic crisis and has ushered in opportunities for development. In the long run, the digital economy's empowerment of traditional industries will become an important engine for economic development. The 2020 Government Work Report proposes continuing to issue support policies, comprehensively promote "internet+" and create new advantages for the digital economy. At present, China is in a critical period of industrial upgrading and a key period of its economic restart after the pandemic. For China to seize the opportunity to create new advantages for the digital economy, it needs to give full credit to the radiative and leading role of the digital economy.

\section{Literature Review on Tax and Fee Reduction}

Different countries have different cultural and social backgrounds and political systems and many scholars have created specific explanations of the impact of the tax burden on economic growth.

2.1. Most Countries Focus on the Study of Individual Income Tax, Corporate Income Tax, Dividend Tax and Value-Added Tax Reduction Policies and Their Effects

A large number of studies examined the effects of tax cuts on different classes, as well as the effect of tax cuts on different economic entities. Rubolino and Waldenstrom (2018) studied the positive impact of lowering the personal income tax rate of high-income groups. Further research by Nallareddy et al. (2018) found that tax cuts increase the capital income of high-income groups. Eissa and Liebman (1996) and Meyer and Rosenbaum (2001) found that tax cuts have obvious incentives for low-income workers' participation in labor. However, Saez et al. (2012) and Romer and Romer (2014) found that tax cuts do not provide significant labor incentives for high-income earners. Benzarti and Carloni (2017) studied the different effects of French value-added tax cuts on different economic entities, finding that there is almost no impact on consumers and business employees and suppliers receive benefits of 16-25\% while business owners receive benefits of $41 \%$. Bell et al. (2019) evaluated the impact of reducing the personal income tax of high-income people in the United States from the perspective of incentive innovation. Saez, Schoefer and Seim (2017), Bennmarker et al. (2013), Skedinger (2014) and Egebaik and Kaunitz $(2013,2017)$ evaluated the impact of the reduction in the Swedish payroll tax rate from an employment perspective while Sahm et al. (2015) evaluated the policy effect of the 2011 salary tax cuts in the United States from the perspective of household balance sheets. Benzarti and Carloni (2017) studied the effect of French value-added tax cuts and Kosonen (2015) studied the effect of Finnish value-added tax cuts.

\subsection{A Large Number of Previous Studies Have Examined the Impact of Tax Reductions on Innovation, Corporate Investment, Employment (Labor Supply), Savings and Consumption}

Dechezlepretre et al. (2016) found that tax cuts have an incentive effect on corporate innovation, while Bell et al. (2019) — examining the perspective of individual investorsfound that reducing the income tax of high-income people has a significant positive incentive for innovation. Chen et al. (2017) found that corporate income tax cuts can also stimulate innovation. Saez et al. (2017) found that lowering the payroll tax of young workers can promote corporate investment. Zwick and Mahon (2017) found that tax cuts have an important impact on small companies' investment behaviors. Chetty and Saez (2005) showed that the 2003 dividend tax cuts in the United States significantly increased corporate dividends but Yagan (2015) found that this did not increase the investments of 
corresponding enterprises. Gourio and Miao (2011) found that unexpected and permanent tax cuts increase investment but unexpected and temporary tax cuts reduce investment in the long run. Zidar's (2017) research using US data after World War II showed that tax cuts can promote employment but the employment effect of tax cuts is related to the size of the benefits that low-income groups receive from tax cuts. Ljungqvist and Smolyansky (2018) showed that tax cuts only significantly promote employment when the economy is in recession. Auerbach (2002)'s simulation study showed that Bush's 2001 tax cuts had negative effects in both the long- and short-term perspectives, while Carroll (2000) used Japan's post-war data to find that permanent income tax cuts cannot immediately increase consumption and aggregate demand.

There have been few studies on the feasibility and sustainability of further tax and fee reductions in China. Gao Peiyong (2017) examined the sustainability perspective of the tax and fee reduction policy and pointed out that direct tax reform with personal income tax and real estate tax as the main content should be promoted. He Daixin (2019) pointed out that the implementation of a new round of larger-scale tax and fee reductions faces challenges in reality and theoretically faces uncertain policy transmission mechanisms and uncertain policy effectiveness. Yan Kun and Yu Shuyi (2018) pointed out that a more feasible tax and fee reduction policy can be achieved by reducing tax perception.

\subsection{The Research Can Be Divided Into Macroscopic and Microscopic Aspects Based on the Perspective of Research Methods and Research Data}

Some past research adopted macro data and VAR or structural measurement model methods to study the policy effects of tax cuts, such as Romer and Romer (2009), Gourio and Miao (2011), House and Shapiro (2006), Auerbach (2002) and Baxter and Crucini (1993). Other past research adopted micro-enterprise data or industry-level data with the use of regression analysis, double difference and other quasi-experimental measurement methods to study the policy effects of tax cuts, such as in Bell et al. (2019), Ljungqvist and Smolyansky (2018), Zidar (2017), Chen et al. (2017), Zwick and Mahon (2017), Benzarti and Carloni (2017) and Yagan (2015).

\section{The Impact of Tax and Fee Reduction on China's Digital Economy from an International Perspective}

Developing the digital economy is the prevalent trend of the world, the opportunity of the times and a crucial market for international competition. China has the world's largest e-commerce market-accounting for $>40 \%$ of all global e-commerce transactions-and its mobile payment transactions are several times that of the United States. China has become an important force in shaping the global digital economy [3]. However, from the perspectives of economic scale, R\&D capacity and overall strength, the United States remains the world's number one digital economy, while China is number two. Competition between these two in terms of the digital economy is inevitable [4]. Therefore, it is imperative to analyze the effect of tax and fee reduction policies on China's digital economy from an international perspective to promote China's digital economy and enhance its international competitiveness [5].

\subsection{The Top 100 List Reflects the Global Digital Economy}

On 11 October 2019, Forbes China released the 2019 Forbes Global Digital Economy Top 100 list, which can be used to analyze the impact of tax and fee reductions on China's digital economy from an international perspective, providing a comparative analysis of the list of enterprises for enhancing the international competitiveness of China's digital economy through tax and fee reductions. Figure 1 shows the number of companies included in Forbes Global Digital Economy Top 100. 


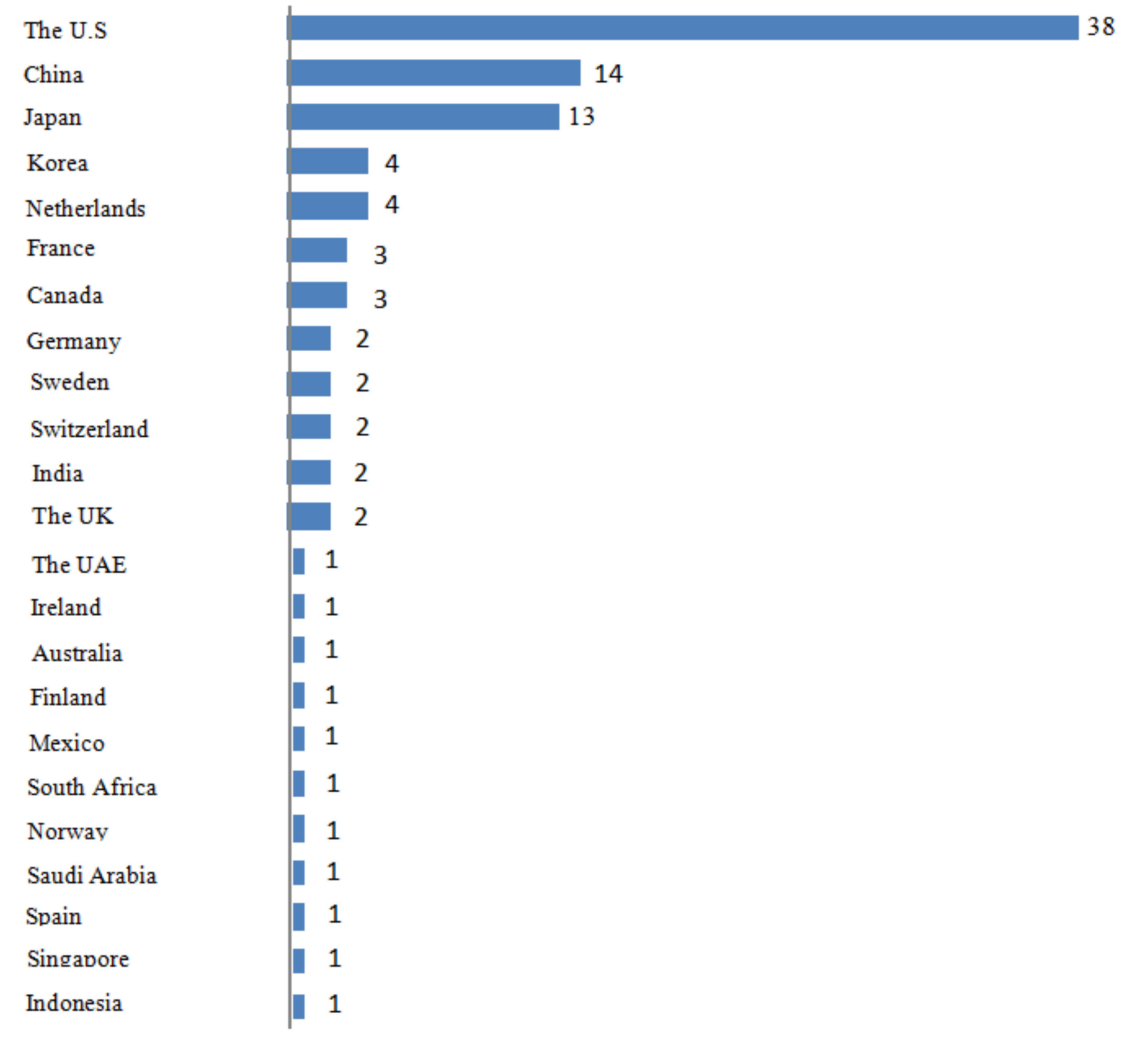

Figure 1. Number of companies included in Forbes Global Digital Economy Top 100.

The companies on the 2019 Forbes Global Digital Economy Top 100 list represent the top level of the digital economy and their distribution, scales and characteristics reflect the development pattern of the global digital economy. The list shows that the United States is the main force in the development of the digital economy. China's leading enterprises in the digital economy strive to reach a relatively leading level but a big gap remains between them and the United States.

3.1.1. The United States Ranks First, in Terms of the Number of Companies on the List, While China Ranks Second

In the 2019 Forbes Global 100 Digital Economy List, the United States and China have the most companies on the list at 38 and 14, respectively (including Hon Hai and TSMC, two Taiwanese companies). There are 52 American and Chinese companies on the list in total, accounting for half of the list. In addition, Japan has 13 companies on the list, South Korea and the Netherlands both have four companies on the list, France and Canada both have three companies on the list, the UK, Germany, Sweden, Switzerland and India have two companies each and Ireland, Australia, Finland and the other 11 countries each have one company on the list. China ranks second on the list, which shows that Chinese digital economy enterprises have strong international competitiveness. However, the number of US companies on the list is 2.7 times that of China, which shows that the American digital economy still takes a commanding lead.

3.1.2. US Companies Dominate the List, While Chinese Companies Are among the Top 10

Among the top 10 in the 2019 Forbes Global 100 Digital Economy List are seven American companies, two Chinese companies and one South Korean company, which reflects that the United States firmly holds a leading position in the digital economy and China is still striving to take the lead in the top 10 in the world. From the perspective of ranking units, the leading companies in the digital economy in the United States have a significant lead on China. Apple (Cupertino, CA, USA) and Microsoft (Redmond, WA, 
USA) were ranked first and second, respectively. In addition, Alphabet, AT\&T, Amazon, Verizon Telecom and Disney were among the top 10 finalists; China Mobile (Beijing, China) and Alibaba ranked seventh and 10th, respectively; and South Korea's Samsung Electronics ranked third.

3.1.3. The US Enterprise Industry Classification Is Extensive, While the Chinese Enterprise Industry Classification Is Relatively Concentrated

According to the classification of companies in the 2019 Forbes Global Top 100 Digital Economy List, US enterprises are distributed in 13 categories: semiconductors, software and programs, computer hardware, business and personal services, internet and catalog sales, computer services, consumer financial services, broadcasting and cable television and entertainment products, thereby covering a wide range. In contrast, Chinese enterprises mainly come from seven categories, including telecommunications services, computer services, Internet and catalog retail and computer hardware. Thus, in many areas of the digital economy, the United States has industry leaders in the top 100, while China's leading digital economy enterprises are involved in relatively few industries. Figure 2 shows the numbers of US and China Digital Economy Companies listed by industry.

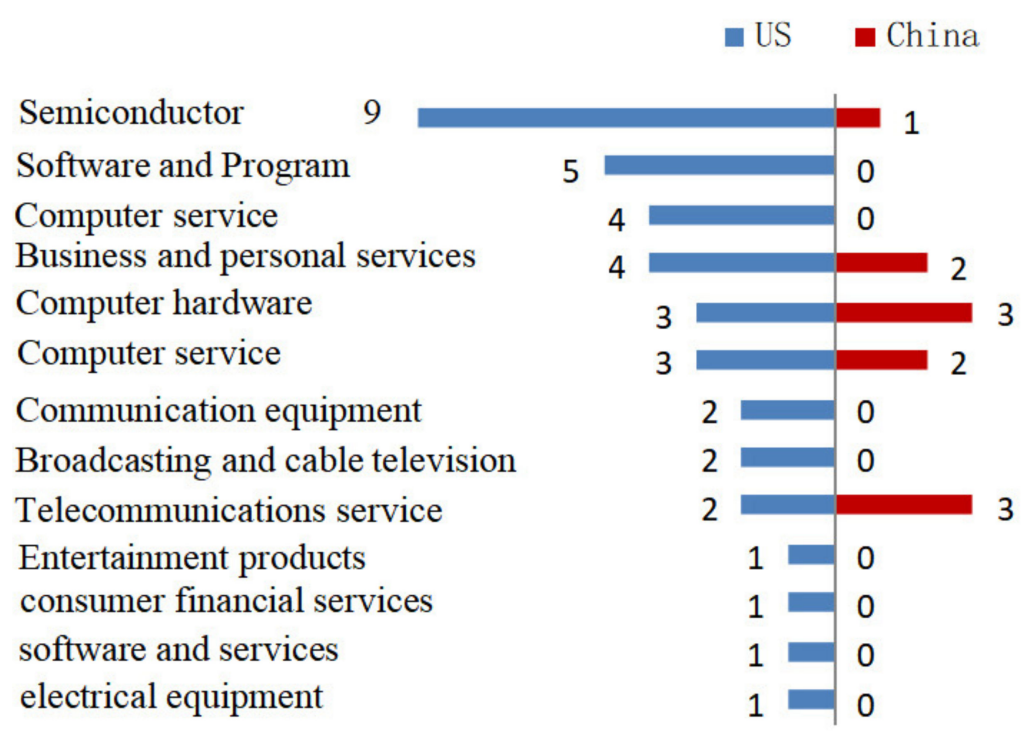

Figure 2. Numbers of US and China Digital Economy Companies listed by industry.

3.2. Tax Cuts and Fee Reductions Help Enhance the International Competitiveness of China's Digital Economy

Referencing the annual report of listed companies in the Wind database (see Supplementary Materials), this paper analyzes the production and operation of the enterprises on the 2019 Forbes Global Top 100 Digital Economy List. We found that over the past five years, with the effective development of the tax and fee reduction policies, China's digital economy has continued to develop rapidly compared with other international leaders. Additionally, its profitability has improved, its tax burden has reduced and its international competitiveness has enhanced.

3.2.1. China's Digital Economy's Main Revenue Growth Rate Is Faster Than That of the United States

In 2015-2019, the main operating revenue of the listed companies in China's digital economy reached 3,609, 3,815, 4,749, 5,277 and 571.6 billion USD, respectively, with an average annual growth rate of $12.2 \%$. The main operating revenue of the listed companies in the US digital economy reached 14,837, 14,940, 16,290, 18,530 and 1,969 billion USD, with an average annual growth rate of $7.3 \%$. China's digital economy has a smaller income 
than that of the United States, but it is catching up, with an average annual growth rate of 4.9 percentage points.

3.2.2. China's Digital Economy Is Growing Faster Than That of the United States in Terms of Net Profit

In 2015-2019, the net profits of the listed companies in China's digital economy were $395,347,401,535$ and 61.9 billion USD, with an average annual growth rate of $11.9 \%$. The net profits of the US digital economy companies on the list were $24,535,27,329,19,705$, 16,290 and 3678.7 billion USD, with an average annual growth rate of $10.7 \%$. The total net profit of China's digital economy is smaller than that of the United States, but the growth trend over the past five years has been faster and more stable than that of the United States, with an average annual growth rate 0.4 percentage points higher than that of the United States.

\subsubsection{China's Digital Economy R\&D Investment Is Growing Faster Than That in the United States}

Digital economy and technology change rapidly and so leading enterprises must actively research and develop to maintain a leading edge in the industry. In 2015-2019, R\&D expenses of the listed companies in China's digital economy were 77, 85, 117, 162 and 18.8 billion USD, with an annual increase of $25 \%$. The R\&D expenses of the listed companies in the US digital economy were 1022, 1131, 1297, 1495 and 171.2 billion USD, respectively, with an average annual growth rate of $13.8 \%$. The scale of $R \& D$ investment in China's digital economy is smaller than that in the United States but the average annual growth rate exceeds that of the United States by 11.2 percentage points, which reflects the strong innovation power and development potential of China's digital economy [6].

\subsubsection{The Income Tax Burden of China's Digital Economy Has Dropped Significantly}

In 2015-2019, the corporate income tax on China's digital economy was 103, 104, 134, 12.9 and 13.2 billion USD, with an average annual growth of $6.2 \%$, which was 5.7 percentage points lower than the growth rate of net profit over the same period. The income tax burden was reduced from $20.4 \%$ to $17.8 \%$, a decrease of 2.6 percentage points, reflecting that the series of tax and fee reduction measures have been effective and that the income tax burden has been significantly reduced. The corporate income tax on the US digital economy list was 690, 565, 553, 694 and 41 billion USD, respectively, with an average annual decrease of $12.2 \%$. The income tax burden had been reduced from $25.3 \%$ to $12.0 \%$, a decrease of 13.3 percentage points, which reflects that the impact of American tax reform on the corporate income tax burden is stronger than that of China. Although the income tax burden of China's digital economy has fallen significantly, it is currently higher than that of the United States $[7,8]$.

\subsection{Empirical Analysis of the Impact of Tax and Fee Reduction on Digital Economy Enterprises from the International Perspective}

To carry out an international comparative analysis of the effects of tax reduction and fee reduction policies on digital economy companies, this paper uses the panel data of global digital economy enterprises for 2015-2019 in the Wind database and uses Stata software to construct a dual-difference Difference-in-difference (DID) model for measurement and analysis.

Data source: the main operating income, operating cost, operating profit, operating profit rate and operating cost rate in the annual report data of listed companies in Wind database.

Sample description: First, in the Wind database, global listed companies in the 2019 Forbes Global Digital Economy Top 100 listed enterprises and some information services listed companies as a supplement with a total of 122 companies. Second, there are 48 large digital economy enterprises in China, 39 in the United States and 35 in other countries and regions. Third, the five-year (2015-2019) data of the abovementioned enterprises will be 
taken. The Comparative data between China and the United States in this research are shown in Table S1 in Supplementary Materials.

Model construction: first, two groups of enterprises were selected from global digital economy enterprises, one of which was the processing group, i.e., the enterprises enjoying the tax reduction and fee reduction policy, to facilitate the comparative analysis with the large-scale tax reduction and fee reduction in 2018 in China and the tax reform in the United States in 2018, the treatment group was further divided into treatment groups 1 (large Chinese digital economy enterprises with large tax cuts) and 2 (large American digital economy enterprises with US tax reform). The other group was the control group, i.e., enterprises without large tax cuts where other countries and regions outside China and the United States as the control group. Then, according to the difference in profitability between the experimental group and the control group before enjoying large-scale tax reductions (tax reform) and the difference in profitability after enjoying large-scale tax reductions (tax reform), the impact of large-scale tax reduction on the profitability of digital economy enterprises was measured. Finally, the differences between treatment group 1 and the control group and between treatment group 2 and the control group were doublechecked to analyze the impact of large-scale tax cuts and fee cuts (tax reform) in both China and the United States on the profitability of digital economy enterprises. Table 1 shows the results:

Table 1. Impact of Tax Reduction on the International Competitiveness of Digital Economy Enterprises.

\begin{tabular}{ccc}
\hline Groups & $\mathbf{( 1 )}$ & (2) \\
\hline Variables & China Operating Profit Margin & United States Operating Profit Margin \\
\hline Tax reduction area * tax reduction & $2.871^{* *}$ & $2.968^{* * *}$ \\
Operating cost rate & $(1.643)$ & $(0.0458)$ \\
& $-0.645^{* * *}$ & $-0.584^{* * *}$ \\
Observations & $(0.0628)$ & $(0.0458)$ \\
R-squared & 415 & 370 \\
Regional fixed effects & 0.266 & 0.425 \\
Time fixed effects & Yes & Yes \\
\hline
\end{tabular}

Note: ${ }^{*}, * *$ and ${ }^{* * *}$ indicate significance at the levels of $10 \%, 5 \%$ and $1 \%$, respectively.

From the calculation results of model (1), the $p$-value of the cross item "tax reduction area * after tax reduction" in the double difference model between China and other countries outside China and the United States is $<0.05$ and the influence coefficient is positive (2.871). This shows that large-scale tax reductions in 2018 had a significant positive impact on the operating profit margin of Chinese digital economy enterprises and improved the international competitiveness of digital economy enterprises.

From the calculation results of model (2), the $p$-value of the cross item "tax reduction area * after tax reduction" in the double difference model between the United States and other countries outside China is $<0.01$ and the influence coefficient is positive $(2.968 *$ ). This shows that the 2018 tax reform had a significant positive impact on the operating profit margin of American digital economy enterprises and improved the international competitiveness of digital economy enterprises.

Compared with the results of the two models, China's large-scale tax cuts in 2018 and the US tax reform in 2018 significantly affected the operating profit margin of domestic digital economy enterprises and enhanced the international competitiveness of domestic digital economy enterprises. The impact effect of the United States was relatively more significant as the impact coefficient was slightly higher. According to the above analysis, China's digital economy is clearly facing great challenges. First, a big gap remains between leading enterprises and international benchmarks. Compared to international benchmarks, China's digital economy still has a lot of room for improvement. In the field of e-commerce, compared to the international benchmark of Amazon, Alibaba's operating revenue and R\&D are smaller. Amazon's (Seattle, WA, USA) operating revenue and R\&D 
costs were 28.05 billion USD and \$35.9 billion USD in 2019, respectively, while Alibaba's were $\$ 71.9$ billion USD and 6.1 billion USD, respectively. In cloud computing, Amazon AWS and Alibaba's cloud revenue in 2018 were 26.6 billion USD and 3.6 billion USD, respectively; the former being seven times larger than the latter. Second, the profit margins and intensity of R\&D investment lag behind developed countries. In the 2019 Forbes Top 100 Digital Economy List, the average net profit margin and R\&D investment intensity of Chinese companies in 2019 were $10.8 \%$ and $3.3 \%$, respectively, while those in the United States were $15.2 \%$ and $8.7 \%$, respectively, with a difference of 4.4 percentage points and 5.4 percentage points, reflecting the fact that compared with the United States, where the digital economy is more developed, the profitability and innovation input of China's digital economy are weaker. Although China's digital economy is growing faster, it still lacks in terms of quantity and quality compared to the United States.

\section{Analysis of the Effects of Tax and Fee Reduction Policies in the Digital Economy}

According to the statistical catalog of digital economy industries, the analysis of the implementation of digital economy tax reduction and fee reduction shows that the scope of tax reduction and fee reduction in the digital economy are expanding and the total amount is increasing, mainly based on enterprise income tax and supplemented by value-added tax. There is more preferential treatment for high-tech encouragement enjoying tax treaty. The amount of tax and fee reductions in the foreign-related digital economy are greater than those of domestic enterprises and the digital economy service industry enjoys preferential treatment compared to the digital economy manufacturing industry, mainly focusing on key software enterprises, R\&D plus deduction, software products value-added tax collection and refund policy. From the scale, large enterprises enjoy the vast majority of tax reductions [9]. Both quantitative and qualitative analyses show that tax reductions and fee reductions play a positive role in promoting the rapid development of the digital economy, accelerating innovation, stabilizing investment, absorbing employment and upgrading the structure [10]. From the point of view of the specific policy of tax reduction and exemption, the preferential tax rate of income tax for key software enterprises, the deduction of $R \& D$ expenses and the preferential amount of software value-added tax are larger. Through the empirical analysis of the digital economy, the effect of tax reduction and fee reduction policies in the digital economy are scientifically evaluated to further optimize the policy and promote development [11].

\subsection{Analysis of Tax and Fee Reduction Policies in the Digital Economy}

With the continuous upgrading and comprehensive implementation of tax and fee reduction policies, tax and fee reductions play an active role in promoting the development of China's digital economy, encouraging technological innovation, expanding effective investment, enhancing social employment, promoting the development of small and microenterprises and optimizing the industrial structure [12]. The essence of digital economy lies in information technology, which requires the development of certain high-tech information technology and industry that involve integrated circuits, communication equipment and facilities, computer hardware and software, network equipment, manufacturing microelectronic products and information and data collection, processing, storage, computing and other service areas [13]. The development of these fields requires innovation and a large amount of early investment; the development of these fields calls for efficiency with the rapidly changing situation and higher risk. It is necessary for the government to share the risk of innovation, reduce the cost of entrepreneurship, lighten the tax burden, increase the profitability, attract capital investment, increase the vitality of the development of digital economy and make efforts to develop the economic quality by adopting policies such as tax and fee reductions. The key to developing the digital economy is technology and innovation [14].

Regarding tax and fee policies, China has no preferential tax or fee policies specifically for the digital economy. However, due to high-tech content in the digital economy and 
the present combination of structure and inclusiveness, under the background of unprecedented tax and fee reductions, taxpayers in the digital economy have enjoyed generous tax and fee reduction policy dividends. From the current tax and fee reduction policies, the preferential tax and fee policies related to the digital economy are mainly innovationrelated policies including encouraging high and new technology, energy conservation and environmental protection, enjoying tax agreement treatments, supporting the financial capital market, promoting the development of small and micro-enterprises, upgrading culture, education and sports, improving people's livelihoods, supporting other undertakings, with tax incentives for nine major categories of relief and 120 relief items. In addition, taxpayers in the digital economy have enjoyed tax reductions such as value-added tax reform and personal income tax reform [15].

\subsection{Macro Analysis of Tax Cuts and Fee Reductions in the Digital Economy}

With the implementation of Chinese larger-scale tax reduction and fee reduction policy, every enterprise and taxpayer has actually enjoyed national tax reduction and fee reduction dividends. Although the pandemic in 2020 has affected economic development, the implementation of the tax reduction and fee reduction policies has played a dual role in enhancing the vitality of market economy entities, reducing operating costs and improving people's livelihoods [16].

\subsubsection{The Direct Effect of "from Tax-to-Tax Base"}

The "scale effect" of tax cuts and fee reduction is prominent. Reducing the tax burden on enterprises by substantially raising the threshold for small-scale taxpayers and allowing small and micro-enterprises to enjoy tax exemptions will reduce the tax burden, especially for private enterprises. Reducing the tax rate and stimulating market vitality by reducing enterprise costs will enhance endogenous motivation and support innovation, start-ups and enterprise investment. The triple tax rate is conducive to balancing the tax burden on manufacturing, business and services and promoting real economic development and economic transformation by promoting the reform of personal tax and increasing residents disposable income to boost consumption. Strengthening the substantive and universal tax reduction, reducing fees and further enhancing policy effectiveness will actively promote the healthy growth and output of private and small and medium-sized enterprises. Substantial tax cuts and fee cuts will further enhance people's sense of happiness, acquisition and security and will inject new vitality, new impetus and new connotations into the construction of a modern socialist country [17].

\subsubsection{Analysis of the Indirect Effects of "from Tax Base to Tax Source"}

The vitality of micro-subjects not only affects the enthusiasm for consumption and production and business activities, but also affects the taxation, employment and other aspects, which in turn affects the economic vitality. Small and medium-sized enterprises not only face difficulties financing and expensive financing but also have a heavy tax burden [18]. Raising the threshold for small and medium-sized taxpayers will allow more enterprises to enjoy tax incentives at lower rates and will support entrepreneurial innovation and the development of small and micro-enterprises with more funding for R\&D and expanding reproduction so that private enterprises-especially small and microenterprises-can enjoy tax and fee reductions and create a better environment for enterprise development [19].

\subsubsection{Analysis of the Macro Effects of "from Tax Source to Economy"}

Excessively low taxes and fees make it difficult to achieve the strategic goal of regulating the economy, adjusting the income gap and regulating the country, while excessively high taxes and fees will increase the burden on microeconomic entities, namely individuals and enterprises, thus restraining the enthusiasm of micro-organizations for consumption, production and management activities, thus affecting the economic vitality [20]. Therefore, 
taxes and fees should be adjusted based on differences and changes in development stages, economic environment and strategic goals. China's implementation of large-scale tax cuts is not an expedient measure; instead, it is an important guarantee and long-term benefit for the sustained and healthy development of the Chinese economy. It is of great significance to maintaining steady and healthy economic development, continuing to deepen and promote supply-side structural reform and better play the role of fiscal policy in expanding domestic demand and structural adjustment [21].

\subsection{Empirical Analysis of Tax and Fee Reductions in the Digital Economy}

To quantitatively analyze the effects of tax reduction and exemption policies in the digital economy, this paper uses Stata software to conduct empirical analysis using tax panel data from 2017-2019.

Data source: business income, total profit, research and development expenses, total asset value, number of employees and tax reduction and exemption data in the account book of tax reduction and exemption accounting.

Sample description: This article uses Stata software to conduct empirical analysis using panel data from a province in 2017-2019. There are 19,515 digital economy enterprises with annual business incomes of $>10,000 \mathrm{RMB}$. According to the classification of operating income, there are 842 large enterprises with an annual operating income of 20 million RMB and 18,673 small, medium and micro-enterprises.

Through the empirical analysis of digital economy and scientific evaluation of the effect of tax and fee reduction policy in digital economy, it is possible to further optimize policies and promote development.

\subsubsection{Impact on Operating Income}

The dependent variable is selected as operating income (YYSR)-reflecting the company's overall output and the independent variable selected as (1) operating cost (YYCB)reflecting the company's cost input; (2) R\&D investment (YF)-reflecting the company's innovation capability; (3) Tax deductions (JMSF)-reflecting the impact of tax deductions (including tax deductions and tax deductions and new tax deductions in 2019).

Model construction:

$$
Y Y S R=c+a_{1} Y Y C B+a_{2} Y F+a_{3} \mathrm{JMSF}+\varepsilon
$$

Table 2 shows the results of the Impact of Tax Reduction on Operating Income. To better analyze the effect of tax reduction and fee reduction policies in the digital economy, the model is calculated by multi-group data of all R\&D sample enterprises, large enterprises and small and medium-sized enterprises. The results show that the R-squared of multiangle data is $>0.83$, which indicates that the model has a high fitting degree and the selected independent variables (operating cost, R\&D investment and tax reduction) can better explain the change in dependent variables (operating income) and the $\mathrm{P}$ values of the respective variables of three groups of data are $<0.1$, which indicates that the operating cost, R\&D investment and tax reduction have a significant impact on the operating income of digital economy [22].

According to the calculation results of large enterprises in the digital economy (2), operating costs, R\&D investment and tax reductions and exemptions have a significant impact on the digital economy's operating income and output. Among them, R\&D investment and tax reductions have a higher impact coefficient. This reflects that the tax reduction of digital economy is $1 \mathrm{RMB}$ and the operating income is increased by $0.534 \mathrm{RMB}$ and the tax multiplier effect appears [23].

From the comparison of data calculation results, the influence coefficient of tax reduction and fee reduction of large enterprises in the digital economy is higher than that of micro, small and medium enterprises, which indicates that increasing the intensity of tax reductions and fee reductions in the digital economy has a significant effect on the industry's development. The impact coefficient of tax and fee reductions is relatively small 
and its pulling effect is weak. This is basically consistent with the fact that micro, small and medium enterprises in the digital economy have relatively low technical content and relatively little tax support [24].

Table 2. Impact of Tax Reduction on the Operating Income of Digital Economy Enterprises.

\begin{tabular}{|c|c|c|c|}
\hline \multirow{2}{*}{ Groups } & (1) & (2) & (3) \\
\hline & Digital Economy & Large Enterprises & Small and Medium-Sized Enterprises \\
\hline VARIABLES & YYSR & YYSR & YYSR \\
\hline \multirow[t]{2}{*}{ YYCB } & $0.584^{* * *}$ & $0.581^{* * *}$ & $1.013^{* * *}$ \\
\hline & $(0.00925)$ & $(0.039)$ & $(0.00623)$ \\
\hline \multirow[t]{2}{*}{ YF } & $0.187 *$ & 0.149 * & $1.040^{* * *}$ \\
\hline & $(0.175)$ & $(0.749)$ & $(0.0468)$ \\
\hline \multirow[t]{2}{*}{ JMSF } & 0.530 * & 0.534 * & $0.285^{* * *}$ \\
\hline & $(0.0517)$ & $(0.217)$ & $(0.0453)$ \\
\hline \multirow[t]{2}{*}{ Constant } & $3,631,235^{* * *}$ & $67,800,000^{* * *}$ & $181.7^{* * *}$ \\
\hline & $(102,558.4)$ & $(4,233,914)$ & $(7490.80)$ \\
\hline Observations & 19,515 & 842 & 18,673 \\
\hline R-squared & 0.9917 & 0.9915 & 0.8316 \\
\hline Number of id & 10,354 & 319 & 10,035 \\
\hline
\end{tabular}

Standard errors in parentheses, ${ }^{* * *} p<0.01,{ }^{* *} p<0.05,{ }^{*} p<0.1$.

\subsubsection{Impact on Profits}

The dependent variable is selected as the total profit (LRZE)-reflecting the profitability of the enterprise and the independent variable is selected as (1) operating cost (YYCB)reflecting the cost input of the enterprise; (2) R\&D investment (YF)-reflecting the innovation ability of the enterprise; (3) Tax reduction and exemption (JMSF)-reflecting the impact of tax reduction and exemption (including tax reduction and exemption amount and new tax reduction and reduction in 2019).

Model construction:

$$
L R Z E=c+a_{1} Y Y C B+a_{2} Y F+a_{3} \mathrm{JMSF}+\varepsilon
$$

Table 3 shows the results of the Impact of Tax Reduction on Profits. To better analyze the effect of tax and fee reduction policies in the digital economy, the model is calculated from the multi-group data of all R\&D sample enterprises, large enterprises and micro, small and medium-sized enterprises. From the results of model calculation, the $p$-value of independent variables (operating cost, R\&D investment and tax reduction and exemption) of multiple groups of data is basically $<0.01$, which indicates that the operating cost, $R \& D$ investment (except for micro, small and medium-sized enterprises) and tax reduction have a significant impact on the total profits in the digital economy. Compared with micro, small and medium-sized enterprises, the influence coefficient of tax reduction on the total profits for large enterprises in digital economy is higher than that of small and medium-sized enterprises, which shows that tax cuts and fee reductions have a more obvious effect on the profitability of large enterprises. The sense of acquisition of large enterprises is easier to improve.

However, the impact of R\&D investment on the digital economy and micro, small and medium-sized enterprises is different; it has a significant positive impact on the total profits of large enterprises (2.337), whereas it has a small impact on micro, small and mediumsized enterprises (0.0045), which shows that the ability of micro, small and medium-sized enterprises to transform R\&D investment into output is lower than that of large enterprises. The process of growth among micro, small and medium-sized enterprises requires the accumulation of early investments such as R\&D and innovation. The risk of R\&D input and output of micro, small and medium-sized enterprises in the entrepreneurial development stage is relatively high. Accordingly, they need policy support and encouragement [25]. 
Table 3. Impact of Tax Reduction on Profits of Digital Economy Enterprises.

\begin{tabular}{cccc}
\hline \multirow{2}{*}{ Groups } & $\mathbf{( 1 )}$ & $\mathbf{( 2 )}$ & $\mathbf{( 3 )}$ \\
\cline { 2 - 4 } & Digital Economy & Large Enterprises & Small and Medium-Sized Enterprises \\
\hline VARIABLES & LRZE & LRZE & LRZE \\
\hline YYCB & $-0.472^{* * *}$ & $-0.475^{* * *}$ & $-0.026^{* *}$ \\
YF & $(0.01790)$ & $(0.07517)$ & $(0.01260)$ \\
JMSF & $2.236^{* * *}$ & $2.337^{*}$ & 0.0045 \\
Constant & $(0.33875)$ & $6.971^{* * *}$ & $(0.0946)$ \\
& $6.952^{* * *}$ & $(0.4197)$ & $0.388^{* * *}$ \\
Observations & $(0.10001)$ & $30,800,000^{* * *}$ & $-34,255.76^{* *}$ \\
R-squared & $1,501,827^{* * *}$ & $(8,187,251)$ & $(15,134.17)$ \\
Number of id & $(198,427.3)$ & 842 & 18,673 \\
\end{tabular}

Standard errors in parentheses ${ }^{* * *} p<0.01,{ }^{* *} p<0.05,{ }^{*} p<0.1$.

\subsubsection{Impact on Investment}

The dependent variable is selected as fixed assets (lngdzc)-reflecting the investment of fixed assets and the independent variable as (1) total profit (lnlrze)-reflecting the profits of the enterprise; (2) tax reduction (lnjmsf)-reflecting the influence of tax reduction and exemptions. To eliminate the influence of the order of magnitude difference between variables, the dependent variables and independent variables are logarithmic.

Model construction:

$$
\operatorname{lng} d z c=c+a_{1} \ln \operatorname{lrz} e+a_{2} \operatorname{lnjmsf}+\varepsilon
$$

Table 4 shows the results of the Impact of Tax Reduction on Investment. To better analyze the effect of tax reduction and fee reduction policy in the digital economy, the model is calculated by multi-group data of all R\&D sample enterprises, large enterprises and micro, small and medium-sized enterprises. From the results of model calculation, the $p$-values of independent variables (total profit, tax reduction and exemption) of multiple groups of data are all $<0.01$, which indicates that the total profit and tax reduction and exemption all significantly impact the investment of fixed assets in the digital economy. Compared with micro, small and medium-sized enterprises, the influence coefficient of tax cuts and fee reductions on fixed assets investment of micro, small and medium-sized enterprises in the digital economy (0.0809) is higher than that of large enterprises (0.064), which shows that tax cuts and fee reductions obviously promotes fixed asset investment in micro, small and medium-sized enterprises. The micro, small and medium-sized enterprises in the digital economy have a low degree of fitting, indicating that other factors that affect the incomes of high-tech products of micro, small, medium-sized enterprises have not been considered. Since the current model can meet the purpose of modeling and analysis in this paper, there will be no further analysis of other factors affecting the income of high-tech products of micro, small and medium-sized enterprises.

Table 4. Impact of Tax Reduction on Investment of Digital Economy Enterprises.

\begin{tabular}{cccc}
\hline \multirow{2}{*}{ Groups } & $\mathbf{( 1 )}$ & $\mathbf{( 2 )}$ & $\mathbf{( 3 )}$ \\
\cline { 2 - 4 } & Digital Economy & Large Enterprises & Small and Medium-Sized Enterprises \\
\hline VARIABLES & LNGDZC & LNGDZC & LNGDZC \\
\hline LNLRZE & $0.029^{*}$ & $0.035^{*}$ & $0.027^{*}$ \\
LNJMSF & $(0.01773)$ & $(0.03816)$ & $(0.02016)$ \\
& $0.075^{* * *}$ & $0.064^{* *}$ & $0.0809^{* * *}$ \\
\end{tabular}


Table 4. Cont.

\begin{tabular}{|c|c|c|c|}
\hline \multirow{2}{*}{ Groups } & (1) & (2) & (3) \\
\hline & Digital Economy & Large Enterprises & Small and Medium-Sized Enterprises \\
\hline VARIABLES & LNGDZC & LNGDZC & LNGDZC \\
\hline Constant & $\begin{array}{c}11.521 \text { *** } \\
(0.235)\end{array}$ & $\begin{array}{c}14.0055^{* * *} \\
(0.5938)\end{array}$ & $\begin{array}{c}10.957^{* * * *} \\
(0.2588)\end{array}$ \\
\hline Observations & 1818 & 325 & 1493 \\
\hline R-squared & 0.1527 & 0.1722 & 0.0241 \\
\hline Number of id & 1251 & 185 & 1066 \\
\hline
\end{tabular}

Standard errors in parentheses, ${ }^{* * *} p<0.01,{ }^{* *} p<0.05, * p<0.1$.

\subsubsection{Impact on Employment}

The dependent variable is selected as the number of employees (lncyrs)-reflecting the employment situation of enterprises-and the independent variable is selected as (1) operating income (lnyysr), which reflects the size of the enterprise's output; (2) tax reduction and exemption (lnjmsf), which reflects the impact of tax reduction. The logarithm of dependent and independent variables is taken to eliminate the influence of dimensional differences among variables.

Model construction:

$$
\operatorname{lncyrs}=c+a_{1} \ln y y s r+a_{2} \operatorname{lnjmsf}+\varepsilon
$$

Table 5 shows the results of the Impact of Tax Reduction on Employment. To better analyze the effect of tax and fee reduction policies in the digital economy, the model is calculated by the multi-group data of all R\&D sample enterprises, large enterprises and micro, small and medium-sized enterprises. From the results of the model calculation, the $P$-value of the independent variables (operating income, tax reduction and exemption) of the data is small, which indicates that the operating income and tax reduction significantly impact the number of employees in the digital economy. From the calculation results, operating income, tax reduction and exemption all significantly impact employment in the digital economy. On the enterprise scale, the coefficients of tax cuts and fee reductions on the employment absorption of large enterprises and micro, small and medium-sized enterprises in the digital economy are similar, which shows that tax cuts and fee reductions have basically the same effect on the promotion of employment by enterprises of different sizes. The low P-value in the model calculation results indicates that the independent variable has a more significant impact on the dependent variable but the R-squared of the model is low, which indicates that other factors that affect the fixed assets of digital economy enterprises have not been considered.

Table 5. Impact of Tax Reduction on the Employment of Digital Economy Enterprises.

\begin{tabular}{cccc}
\hline \multirow{2}{*}{ Groups } & $\mathbf{( 1 )}$ & $\mathbf{( 2 )}$ & $\mathbf{( 3 )}$ \\
\cline { 2 - 4 } & Digital Economy & Large Enterprises & Small and Medium-Sized Enterprises \\
\hline VARIABLES & LNCYRS & LNCYRS & LNCYRS \\
\hline LNYYSR & $0.071^{* * *}$ & 0.0635 & $0.0727^{* * *}$ \\
& $(0.0216)$ & $(0.11674)$ & $(0.01066)$ \\
LNJMSF & $0.0109^{*}$ & $0.0875^{*}$ & $(0.0056)$ \\
Constant & $(0.0063)$ & $(0.5147)$ & $0.338^{* *}$ \\
Observations & $0.3544^{* *}$ & 0.9896 & $(0.13655)$ \\
R-squared & $(0.1582)$ & $(2.0397)$ & 12,827 \\
Number of id & $13,377^{* * *}$ & 0.1088 \\
\hline
\end{tabular}




\subsubsection{Impact on Revenue of High-Tech Products}

The selected dependent variable is high-tech product income (GXJSCPSR), which reflects the output of digital economy high-tech products and the selected independent variables are (1) operating income (YYSR), which reflects the scale of enterprise output; (2) R\&D expenditure input, which reflects enterprise innovation input; (3) tax reduction (JMSF), which reflects the impact of tax reduction and exemption.

Model construction:

$$
\operatorname{GXCPSR}=c+a_{1} \mathrm{YF}+a_{2} \mathrm{JMSF}+\varepsilon
$$

Table 6 shows the results of the Impact of Tax Reduction on Revenue of High-tech Products. To better analyze the effects of tax and fee reduction policies in the digital economy, the model is calculated using the multi-group data of all R\&D sample enterprises, large enterprises and micro-, small- and medium-sized enterprises. The results show that the $p$-values of the variables of multiple sets of data are each $<0.01$, which indicates that the $R \& D$ investment and tax reduction and exemption significantly influence the income of high-tech products in the digital economy. This model can better explain the changes in income from high-tech products. The influence coefficient of tax cuts and fee reductions on high-tech products of micro-, small- and medium-sized enterprises in the digital economy is higher than that of large enterprises; if taxes and fees were reduced in the digital economy by $1 \mathrm{RMB}$, it would drive the income of its high-tech products to increase by $2.512 \mathrm{RMB}$. Thus, the tax multiplier effect appears. The R-squared calculated by the data is around 0.25 , which indicates that digital economy companies have a high degree of fitting.

Table 6. Impact of Tax Reduction on the Revenue of High-tech Products of Digital Economy Enterprises.

\begin{tabular}{cccc}
\hline \multirow{2}{*}{ Groups } & $\mathbf{( 1 )}$ & $\mathbf{( 2 )}$ & $\mathbf{( 3 )}$ \\
\cline { 2 - 4 } & Digital Economy & Large Enterprises & Small and Medium-Sized Enterprises \\
\hline VARIABLES & GXCPSR & GXCPSR & GXCPSR \\
\hline YF & $2.849^{* * *}$ & $2.915^{* * *}$ & $\left(.987^{* * *}\right.$ \\
& $(0.14018)$ & $0.5993)$ & $(0.1722)$ \\
JMSF & $0.338^{* * *}$ & $(0.1751)$ & $\left(0.512^{* * *}\right.$ \\
& $(0.04172)$ & $2.4200000^{* * *}$ & 6538.114 \\
Constant & $1^{*}, 029,010^{* * *}$ & $(1,762,481)$ & $(33,057.94)$ \\
Observations & $(74,654.53)$ & 842 & 18,673 \\
R-squared & 19,515 & 0.2528 & 0.2793 \\
Number of id & 0.2844 & 319 & 10,035 \\
VARIABLES & 10,354 & GXCPSR & GXCPSR \\
YF & GXCPSR & $2.915^{* * *}$ & $1.987^{* * *}$
\end{tabular}

Standard errors in parentheses, ${ }^{* * *} p<0.01,{ }^{* *} p<0.05,{ }^{*} p<0.1$.

\subsubsection{Impact on R\&D Investment}

The dependent variable is selected as research and development expenses (lnyf, reflecting the innovation input of digital economy and the independent variables are selected as (1) operating income (lnyysr, reflecting the scale of enterprise output) and (2) tax reduction (lnjmsf, reflecting the impact of tax reduction and exemption). To eliminate the influence of the order of magnitude difference between variables, the dependent and independent variables are logarithmic.

Model construction:

$$
\ln y f=c+a_{1} \operatorname{lnyysr}+a_{2} \operatorname{lnjmsf}+\varepsilon
$$

Table 7 shows the results of the Impact of Tax Reduction on R\&D Investment. To improve the analysis of the effects of digital economy tax reduction and fee reduction 
policy, this paper still conducts model calculations based on multiple sets of data from all R\&D sample companies (large companies and micro, small, medium-sized enterprises). From the results of model calculation, the P-values of the variables of the multiple sets of data are each $<0.01$, showing that both operating income and tax reduction and exemption significantly impact R\&D investment in the digital economy. This reflects that tax and fee reductions in the digital economy have increased by $1 \%$, which has driven R\&D investment to increase by $0.0253 \%$.

Table 7. Impact of Tax Reduction on the R\&D Investment of Digital Economy Enterprises.

\begin{tabular}{cccc}
\hline \multirow{2}{*}{ Groups } & $\mathbf{( 1 )}$ & $\mathbf{( 2 )}$ & $\mathbf{( 3 )}$ \\
\cline { 2 - 4 } & Digital Economy & Large Enterprises & Small and Medium-Sized Enterprises \\
\hline VARIABLES & LNYF & LNYF & LNYF \\
\hline LNYYSR & $0.556^{* * *}$ & $0.0635^{*}$ & $0.5706^{* * *}$ \\
& $(0.0792)$ & $(0.11674)$ & $(0.07710)$ \\
LNJMSF & $0.0253^{*}$ & $0.0875^{*}$ & $(0.0311)$ \\
& $(0.0278)$ & $(0.5147)$ & $3.798^{* * *}$ \\
Constant & $4.2218^{* * *}$ & $(2.0397)$ & $(1.0685)$ \\
Observations & $(1.1720)$ & 235 & 745 \\
R-squared & 980 & 0.1418 & 0.3181 \\
Number of id & 0.4936 & 114 & 509 \\
\hline
\end{tabular}

Standard errors in parentheses, ${ }^{* * *} p<0.01,{ }^{* *} p<0.05,{ }^{*} p<0.1$.

\section{Problems of Tax and Fee Reduction and Policies in China's Digital Economy}

\subsection{Lack of Specialized Preferential Tax Policies for the Digital Economy}

China has not yet formulated specialized preferential tax policies for the digital economy. The preferential tax policies currently applied to digital economy enterprises are mainly concentrated on the state: encouraging industries and products such as preferential income tax for high-tech enterprises, additional deductions of R\&D expenses, preferential income tax rate for key software enterprises and immediate refunding of value-added tax for software products, plus the programs for improving people's livelihoods and supporting small and micro businesses. In terms of the number of projects, although $>100$ items are involved, they are scattered across various categories relatively unsystematically.

\subsection{Improvement on Preferential Tax Policies Needed to Encourage Innovation}

Modern China's digital economy enterprises face challenges of relatively archaic core technology and the absence of core industries, which ultimately results from a lack of innovation input and innovation ability. At present, the preferential tax policies for digital economy enterprises' income mainly focus on the achievement of transformation and the introduction of advanced technology; less focus is placed on support for prior research and development, which mostly benefits enterprises with strong innovation ability but rarely covers enterprises that need immediate support in their incubation period [26]. Under the influence of such incentive-based policies, enterprises automatically attach importance to importing advanced technology and making high-tech products, with an inadequate input on key R\&D. This leads to a series of problems: repeating the import of assembly lines requires an excessive production capacity of end products and an insufficient capacity for developing intermediate products, related products and some important raw materials [27].

\subsection{High Marginal Tax Rate for Personal Income Tax Unappealing to Talents}

The global competition among digital economy enterprises is increasingly fierce; the same is true of talent. Concerning the highest marginal tax rate for individual income tax, it is too high in China to attract overseas top talents at up to $45 \%$, compared with $37 \%$ in the United States (2017), 33\% in Canada and 38\% in South Korea. Thus far, China has introduced individual income tax concessions for talent and for specific regions (Guangdong, 
Hong Kong and Macao); this context still prevents talented individuals from working hard and innovating, which is attributed to the narrow coverage and high entry barrier of tax concessions [28].

\subsection{A Big Enterprise Income Tax Burden against International Competition}

Over the past two years, digital economy enterprises' income tax burden has decreased significantly in China but the decrease in the United States has been even greater. Based on the data obtained for the top 100 digital economy enterprises, the income tax burden placed on China's digital economy corporations in 2019 is up to $17.6 \%$. In contrast, that in the United States is $12.1 \%$. In the fierce international market competition, the income tax policies for Chinese corporations are neither competitive nor attractive.

\section{Policy Recommendations for Tax and Fee Reductions in the Digital Economy}

The world economy is witnessing more profound changes than any seen in any other century. The Chinese economy is also in a critical period of economic restart after the pandemic. It is urgent that it plays a leading role in the digital economy and continuously enhances its economic innovation, competitiveness and sustainable development [29,30]. Through targeted research and literature review, this paper finds that research space remains. Through empirical analysis of China's "tax reduction and fee reduction" in recent years and research evaluating its policy system, this paper aims to adjust the research direction of tax policy according to the direction of tax policy changes. This paper chooses the core industry perspective of the digital economy: based on economic theory, it theoretically analyzes the relationship between "tax and fee reductions" and the development of the digital economy industry to empirically study the policy effects of China's "tax and fee reductions." With the continuous introduction of China's tax and fee reduction policies, such as the newly introduced preferential policies during the 2020 pandemic, there is still room for continuous research. It is necessary to analyze the feasibility of implementing further tax and fee reductions based on theoretical and empirical research results. In response to the challenges faced by the digital economy and the tax-and fee-reduction policies, it is necessary to continuously improve and optimize tax and fee policies to promote high-quality development of China's digital economy and help cultivate and develop a group of leading companies in the digital economy [31,32].

\subsection{Optimizing the Tax and Fee Policy System Should Be Done in Coordination with the Digital Economy Development Strategy}

The digital economy represents the future direction of development and is therefore of pressing importance. It is recommended to formulate a tax and fee reduction policy system that conforms to the laws of digital economy development in accordance with the characteristics and development status of the digital economy industry. It is necessary to solidify the advantages of the existing tax and fee preferential policies that encourage high-tech development. In addition, the formulation of tax cut and fee reduction policies, in addition to fiscal and taxation tools, should differ from high-tech industrial policies. It is recommended that fiscal appropriations, loan interest discounts and tax reduction and rebate policies be used in a comprehensive manner to form a joint policy [33].

\subsection{Increase Tax Incentives for New Enterprises}

Entrepreneurship is both an important step in the transformation and commercialization of scientific and technological achievements and an important conduit of innovation. Entrepreneurship in the digital economy is risky and a considerable number of new enterprises fail in their first few years. Based on the consideration of entrepreneurial risk and the hope for the future prospects of new enterprises, many foreign countries or regions attach great importance to tax support policies for new enterprises such as the implementation of offsetting investment losses and tax credits with other income for venture capital enterprises and the implementation of reduced tax rates or tax deductions for new ventures [34]. Compared with foreign practices and experiences, most current tax policies 
in China focus mainly on enterprises that have basically solved their survival problems and have a certain foundation for development, such as the $15 \%$ income tax reduction policy for high-tech enterprises and the policy of additional tax deductions for enterprise R\&D; this implies that such enterprises already meet the preconditions for independent intellectual property rights of certain profitability and income level and it is difficult for newly founded companies to meet the basic requirements to enjoy these tax incentives [35].

\subsection{Increase Tax Incentives for Employment-Related High-Level Talent}

Talent is the key to both innovation in the digital economy and to improving its core competitiveness. However, China's current personal income tax system has a top tax rate of $45 \%$, which fails to provide effective tax incentives for high-wage earners. To increase the welfare of talent and stimulate talent innovation in the digital economy, salary for talented individuals is increased given the low proportion of after-tax income and low marginal utility of wages and salaries, which affects the incentive effect of talented individuals. A burden is laid on talent motivation in the digital economy [36]. In addition, it is not conducive to the expansion of employment and the placement of employment for digital economy enterprises. In view of the characteristics of the digital economy industry and talent, international enterprises generally offer high salaries to attract and retain talent. Equity incentives and annuity systems have also become important aspects of enterprise compensation systems and salaries in the digital economy are generally higher [37].

\subsection{Increase Tax Incentives for Independent Innovation Based on Research and Development}

The development of the digital economy cannot be separated from independent innovation. Most countries and regions have established R\&D tax incentive systems with indirect incentives and direct incentives as auxiliaries, such as pre-tax deductions of $R \& D$ expenses, forward or backward carry-over and the extraction of scientific research reserves. In contrast, China's current tax policy has been greatly improved in this respect, such as the pre-tax deduction policy for enterprise R\&D expenses that has significantly impacted digital economic innovation; nevertheless, it still needs further improvements to give full play to the tax multiplier effect [38]. High-tech enterprises are often the main body of R\&D technology. The promotion of tax and fee reductions on enterprise R\&D and hightech product income will effectively promote both the self-upgrading of enterprises and industrial development [39].

\subsection{Increase Investment to Promote the Transformation and Upgrading of Manufacturing}

From a supply perspective, tax cuts and fee reductions will enhance market entities' ability to expand investment [40]. Take China's manufacturing industry as an example. The tax revenue it provides accounts for about $30 \%$ of the total tax revenue and the value-added tax it provides accounts for $60 \%$ of the total value-added tax. The expansion in scale and the structural adjustment of the manufacturing industry are inseparable from those of the logistics industry. For logistics companies that purchase a large number of machines and equipment and build, renovate and expand logistics facilities during their period of scale expansion, the tax reduction benefit from lowering the value-added tax rate is the greatest. Clearly, lowering the tax rate has formed a two-way (upstream and downstream) complementary incentive mechanism for the development of the real economy [41]. The manufacturing industry has a strong function that is of extraordinary significance to sustained economic prosperity and social stability [42]. Manufacturing companies should seize the favorable opportunity of reducing taxes and fees and invest more funds in innovative $R \& D$ and the expansion of reproduction, thereby promoting the transformation and upgrading of the entire industry, enhancing competitiveness, alleviating downward pressure on the economy and enhancing resistance ability [43].

Supplementary Materials: The following are available online at https:/ /www.mdpi.com/article/10 $.3390 /$ su13147611/s1, Table S1: Comparative data between China and the United States shown in this research. 
Author Contributions: Conceptualization, T.L.; methodology, L.Y.; software, L.Y.; validation, L.Y.; formal analysis, L.Y.; investigation, T.L. and L.Y.; data aggregation, L.Y.; writing一original draft preparation, L.Y.; writing-review and editing, T.L. and L.Y.; All authors have read and agreed to the published version of the manuscript.

Funding: This research received no external funding.

Data Availability Statement: The main operating income, operating cost, operating profit, operating profit rate and operating cost rate are in the annual report data of the Wind database (Supplementary Materials).

Conflicts of Interest: The authors declare no conflict of interest.

\section{References}

1. China Institute of Information and Communications Technology. White Paper on Digital Economic Development and Employment in China; China Institute of Information and Communications Technology: Beijing, China, 2019.

2. Brandt, L.; Biesebroeck, J.V.; Zhang, Y. Creative accounting or creative destruction? Firm-level productivity growth in Chinese manufacturing. J. Dev. Econ. 2012, 97, 339-351. [CrossRef]

3. Yang, Y.; Zheng, L.; Xiaoqian, Y. Challenges and Solutions of Enterprise Income Tax in Digital Economy-Based on the International Comparative Perspective. Friends Account. 2018, 7, 73-79.

4. Auerbach, A.J. The Bush Tax Cut and National Saving. Natl. Tax J. 2002, 55, 387-407. [CrossRef]

5. Reed, W.R. The Robust Relationship between Taxes and US State Income Growth. Natl. Tax J. 2008, 61, 57-80. [CrossRef]

6. Lisan, Z.; Zinan, W. Analysis on the Relationship between Income Tax Incentives and R\&D investment based on Enterprise Profitability. Tax Res. 2020, 5, 113-119. [CrossRef]

7. Yeguang, C.; Jing, W. Research on the effect of Income Tax R\&D Expenses Plus Deduction Policy based on China's Three Economic Zones. Tax Res. 2020, 2, 92-98.

8. Bell, A.M.; Chetty, R.; Jaravel, X.; Petkova, N.; Van Reenen, J. Do Tax Cuts Produce More Einsteins? The Impacts of Financial Incentives vs. Exposure to Innovation on the Supply of Inventors; NBER Working Paper No. 25493; NBER: Cambridge, MA, USA, 2019.

9. Baum, D.N. Economic Effects of Including Services in the Sales Tax Base: An Applied General Equilibrium Analysis. Public Financ. Rev. 1991, 19, 166-192. [CrossRef]

10. Surong, W.; Bo, F. Analysis of the P olicy Effect of Value-added Tax Transformation. Econ. Res. Guide 2011, $22,16-18$.

11. Husheng, W. Research on the Construction of Tax Expenditure System Based on Efficiency Optimization. Tax Res. 2020, 1, $122-128$.

12. Helms, L.J. The Effect of State and Local Taxes on Economic Growth: A Time Series Cross Section Approach. Rev. Econ. Stat. 1985, 67, 574-582. [CrossRef]

13. Jianfu, S.; Jia, H. Analysis of the Effect of Tax Preference on the Development of Integrated Circuit Enterprises in China. Tax Res. 2020, 2, 23-30.

14. Chao, H. Analysis of Tax Preferential Policies in China's Integrated Circuit Industry. Tax Res. 2020, 2, 33-36.

15. Gentry, W.M.; Ladd, H.F. State Tax Structure and Multiple Policy Objectives. Natl. Tax J. 1994, 47, 747-769. [CrossRef]

16. Degang, L.; Lingjiang, G. Path optimization of tax reduction and fee reduction in the new era. Tax Res. 2020, 4, $29-32$.

17. Daixin, H. Challenges and Countermeasures in implementing larger scale tax reduction. Tax Res. 2019, $2,18-20$.

18. Surong, W.; Fang, Y. Tax reduction and fee reduction: Mechanism, measures and micro effects. Financ. Res. 2020, 1, 18-25. [CrossRef]

19. Bin, Z. Theoretical dimension, policy framework and realistic choice of tax reduction and fee reduction. Financ. Res. 2019, 5, 7-16. [CrossRef]

20. Romer, C.D.; Romer, D.H. Do Tax Cuts Starve the Beast? The Effect of Tax Changes on Government Spending Brookings Papers on Economic Activity; Economic Studies Program; The Brookings Institution: Washington, DC, USA, 2009; Volume 40, pp. 139-214.

21. Kun, Y.; Zhen, J. Key points and policy suggestions for implementing strategic tax reduction. Tax Res. 2019, 7, 3-7.

22. Auerbach, A.J. Tax Reform and Adjustment Costs: The Impact on Investment and Market Value. Int. Econ. Rev. 1989, 30, 939-962. [CrossRef]

23. Francois, G.; Miao, J. Transitional Dynamics of Dividend and Capital Gains Tax Cuts. Rev. Econ. Dyn. 2011, 14, $368-383$.

24. Angelopoulos, K.; Economides, G.; Kammas, P. Tax-spending Policies and Economic Growth: Theoretical Predictions and Evidence from the OECD. Eur. J. Political Econ. 2007, 23, 885-902. [CrossRef]

25. Leiming, Y.; Bo, Z.; Yu, S.; Tan, Y. Analysis of the effect of substantial tax reduction: From the perspective of preventing and resolving major economic risks. Tax Res. 2020, 4, 24-28.

26. Zhang, L.; Chen, Y.; He, Z. The effect of investment tax incentives: Evidence from China's value-added tax reform. Int. Tax Public Financ. 2018, 25, 913-945. [CrossRef]

27. Pingfang, Z.; Weimin, X. Effects of the Government's Science and Technology Incentive Policy on R\&D Input and Patent Output of Large and Medium-sized Industrial Enterprises-An Empirical Study of Shanghai. Econ. Res. 2003, 6, 45-53+94.

28. Allingham, M.G.; Sandmo, A. Income Tax Evasion: A Theoretical Analysis. J. Public Econ. 2010, 3, 201-202. [CrossRef] 
29. Zheng, W.P.; Zhang, J. Does tax reduction spur innovation? Firm-level evidence from China. Financ. Res. Lett. 2020, 101575. [CrossRef]

30. Liping, D. The concept of tax reduction with Chinese characteristics. Contemp. Financ. Econ. 2019, 6, $28-35$.

31. Xu, J.; Wei, W.X. The effects of tax and fee reduction policy on mitigating shock of the COVID-19 epidemic in China. Appl. Econ. 2021. [CrossRef]

32. Brennan, G.; Buchanan, J.M. The Power to Tax: Analytical Foundations of a Fiscal Constitution. South. Econ. J. 1980, 48, 221-225.

33. Jiancheng, G. Tax reduction, economic growth and market interest rate. Macro Res. 2019, 8, 59-63.

34. Levinsohn, J.; Petrin, A. Estimating Production Functions Using Inputs to Control for Unobservables. Rev. Econ. Stud. 2003, 70, 317-341. [CrossRef]

35. Chaoji, Y. A new round of tax reduction to promote the development of private enterprises. Theor. Discuss. 2020, 1, 96-101. [CrossRef]

36. Gobey, M.; Matikonis, K. Small business property tax reductions and job growth. Small Bus. Economics 2021, 56, $277-292$. [CrossRef]

37. Wang, Y.; Yao, Y. Sources of China's Economic Growth 1952-1999: Incorporating Human Capital Accumulation. China Econ. Rev. 2003, 14, 32-52. [CrossRef]

38. Cangfeng, W. Tax Relief and R\&D Investment: An Empirical Analysis Based on the Data of Chinese Manufacturing Enterprises. Tax Res. 2009, 11, 25-28.

39. Yang, C.-H.; Huang, C.-H.; Chang, W.-H. Does Reduction in the Tax Credit Rate Retard R\&D Activity? Evidence from Taiwan's R\&D Tax Cred-It Reform in 2010. Contemp. Econ. Policy 2021, 398-415. [CrossRef]

40. Liu, Y.; Mao, J. How Do Tax Incentives Affect Investment and Productivity? Firm-Level Evidence from China. Am. Econ. J. Econ. Policy 2019, 11, 261-291. [CrossRef]

41. Khastar, M.; Aslani, A.; Nejati, M. How does carbon tax affect social welfare and emission reduction in Finland? Energy Rep. 2020, 6, 736-744. [CrossRef]

42. Kim, S.; Park, J.-H. Dynamic factor adjustment and corporate tax reduction in the Japanese manufacturing industry. J. Asia Pac. Economy 2020. [CrossRef]

43. Seip, K.L. Does tax reduction have an effect on gross domestic product? An empirical investigation. J. Policy Modelling 2019, 41, 1128-1143. [CrossRef] 